\title{
MACRONUTRIENTS WATERS OF IRRIGATION ON A PROPERTY OF ORGANIC PRODUCTION IN PARANAGUÁ - PR
}

\author{
REIS, Camila Salles dos; CAVALLET, Luiz Ermindo; ROCHA, José Roberto Caetano da*; \\ Faculdade de Filosofia, Ciências e Letras de Paranaguá, Departamento de Ciências Biológicas, R. \\ Comendador Correia Júnior, 117, CEP 83203-560, Paranaguá - PR, Brasil \\ (fone: +55 413423 3644; fax: +55 413423 1611) \\ * Autor correspondente \\ e-mail: jose.rocha@fafipar.br
}

Received 10 December 2013; received in revised form 28 January 2014; accepted 02 February 2014

\section{RESUMO}

Neste trabalho são apresentados os resultados dos ensaios espectrofotométricos realizados nas amostras retiradas das águas da propriedade de produtos orgânicos, localizada no município de Paranaguá, bem como outros ensaios físico-químicos das referidas amostras. Os mesmos foram realizados para avaliar a propriedade orgânica. Os ensaios espectrofotométricos foram realizados para quantificar o elemento químico fósforo pelo método do azul de molibdênio e o elemento químico nitrogênio pelos métodos de Griess e Indofenol. Esses elementos químicos apresentam baixa disponibilidade natural e são macronutrientes importantes para o crescimento de plantas. Com os resultados obtidos se constatou que as concentrações do elemento nitrogênio estão abaixo dos limites especificados pela Resolução 357/2005 do CONAMA. Já o íon fosfato apresentou elevadas concentrações nas amostras de água que foram retiradas dos dois pontos específicos da propriedade orgânica. Nas amostras retiradas do primeiro ponto de amostragem observou-se que os níveis de fosfato presente foram mais altos do que dos resultados obtidos das amostras retiradas do segundo ponto, denotando que a alta concentração de fosfato provavelmente é devido a níveis elevados de fosfatos do solo e não de um depósito antrópico realizado pelo produtor rural. Dessa forma conclui-se que a concentração elevada do íon fosfato é natural.

Palavras-chave: Determinação espectrofotométrica, macro-nutriente, fosfato, nitrogênio.

\section{ABSTRACT}

In this work the results of spectrophotometric assays performed on samples taken from the waters of ownership of organic products, located in the municipality of Paranaguá, as well as other physical and chemical testing of these samples are presented. They were conducted to evaluate the tissue property. The spectrophotometric assays were performed to quantify the chemical element phosphorus by the molybdenum blue method and nitrogen chemical element methods by Griess and Indophenol. These chemicals have low natural availability and macronutrients are important for the growth of plants. With the results it was found that the concentrations of the element nitrogen are below the limits specified by Resolution 357/2005 of CONAMA. Have phosphate ions showed higher concentrations in the water samples were taken from two specific points of organic property. In the samples from the first sampling point was observed that the levels of phosphate present were higher than the results obtained from samples taken from the second point, indicating that high phosphate concentration is likely due to high levels of soil phosphates and not an anthropic deposit held by the farmer. Thus it is concluded that the high concentration of phosphate ion is natural.

Keywords: Spectrophotometric determination, macronutrient, phosphate, nitrogen.

PERIÓDICO TCHÊ QUÍMICA • www.periodico.tchequimica.com・ Vol. 11 N. 22.

• ISSN 1806-0374 (impresso) • ISSN 1806-9827 (CD-ROM) • ISSN 2179-0302 (meio eletrônico)

(C) 2014. Porto Alegre, RS. Brasil 


\section{INTRODUÇÃO}

Os ecossistemas aquáticos incorporam, ao longo do tempo, substâncias provenientes de causas naturais, ou seja, sem nenhuma contribuição humana. Essas concentrações raramente são elevadas, no entanto, podem afetar o comportamento químico dos recursos hídricos e seus usos mais relevantes. Entretanto, outras substâncias lançadas nos corpos d'água pela ação antrópica, ou seja, em decorrência da ocupação e do uso do solo, resultam em sérios problemas de qualidade de água, que demandam investigações e investimentos para sua recuperação (INEA, 2013).

Essas atividades humanas tem causado o crescente enriquecimento artificial dos ecossistemas aquáticos pelo excesso de nutrientes, principalmente daqueles que tem em sua estrutura química os elementos nitrogênio e fósforo. Essas substâncias são provenientes da utilização de fertilizantes na agricultura, da descarga de esgotos industriais e domésticos sem tratamento adequado, destruição da mata ciliar dos mananciais, alta taxa de urbanização e falta de saneamento básico (Carvalho et al, 2013).

O crescente descarte de macro-nutrientes em corpos hídricos provoca 0 processo de eutrofização das águas. As principais características desse processo são mudanças na qualidade da água. Entre estas é possível citar a redução do oxigênio dissolvido, a mortalidade de peixes, o decréscimo na diversidade de espécies da comunidade fitoplanctônica e aumento da incidência de florações de algas e cianobactérias potencialmente produtoras de toxinas (Field, et al, 1998, Schindler et al, 2008). Outros fatores, como a baixa profundidade média do corpo hídrico, o grande tempo de residência e a intensa ocupação urbana e agropastoril nas áreas de entorno de reservatórios também favorecem este fenômeno (Carvalho et al, 2013).
O processo de eutrofização pela ocupação por agricultura, onde ocorre a retirada da vegetação natural da bacia para ocupação por agricultura representa, usualmente, uma etapa intermediária no processo de deterioração de um corpo d'água. Os vegetais plantados na bacia são retirados para consumo humano, muito possivelmente fora da própria bacia hidrográfica. Com isto, há uma retirada, não compensada naturalmente, de nutrientes, causando a quebra no ciclo interno dos mesmos. Para compensar esta retirada, e para tornar a agricultura mais intensiva, são adicionados artificialmente fertilizantes, isto é, produtos com elevados teores dos nutrientes nitrogênio e fósforo. Os agricultores, visando garantir uma produção elevada, adicionam quantidades elevadas de nitrogênio e fósforo, frequentemente superiores à própria capacidade de assimilação dos vegetais (Von Sperling, 1996).

Esta prática não é permitida em áreas de produção de culturas orgânicas, visto que "considera-se sistema orgânico de produção agropecuária, todo aquele em que se adotam técnicas específicas, mediante a otimização do uso dos recursos naturais e socioeconômicos disponíveis. Além do respeito à integridade cultural das comunidades rurais, tendo por objetivo a sustentabilidade econômica e ecológica, a maximização dos benefícios sociais, a minimização da dependência de energia não renovável. Empregando, sempre que possível, métodos culturais, biológicos e mecânicos, em contraposição ao uso de materiais sintéticos. Com a eliminação do uso de organismos geneticamente modificados e radiações ionizantes, em qualquer fase do processo de produção, processamento, armazenamento, distribuição e comercialização, e a proteção do meio ambiente" (Brasil, 2003)

O fósforo é, em razão da sua baixa disponibilidade em regiões de clima tropical, o nutriente mais importante para o crescimento de plantas aquáticas. Quando esse crescimento ocorre de forma exacerbada é devido a presença em excesso desse produto. E assim prejudica os usos desse recurso hídrico caracterizado pelo fenômeno conhecido como eutrofização (Brasil, 2006).

Outro elemento químico importante para esse 
processo é o nitrogênio, visto que o mesmo auxilia no crescimento de algas e macrófitas (plantas aquáticas superiores), sendo facilmente assimilável nas formas de nitratos e amoniacal. Em condições fortemente alcalinas, ocorre o predomínio da amônia livre (ou não ionizável), que é bastante tóxica a vários organismos aquáticos. Já o nitrato, quando ingerido pelo homem em concentrações elevadas, está associado à doença Metemoglobinemia (Nascimento et al, 2008), que dificulta o transporte de oxigênio na corrente sanguínea de bebês. Em adultos, a atividade metabólica interna impede a conversão do nitrato em nitrito, que é 0 agente responsável por essa enfermidade. Além de ser fortemente encontrado na natureza, na forma de proteínas e outros compostos orgânicos, o nitrogênio tem uma significativa origem antropogênica, principalmente em decorrência do lançamento, em corpos d'água, de despejos domésticos, indústrias e de criatórios de animais, assim como de fertilizantes (Brasil, 2006).

\section{DESENVOLVIMENTO}

Foram retiradas amostras de água em dois pontos de amostragem, que são utilizadas para a irrigação dos cultivos orgânicos na propriedade localizada no município de Paranaguá - PR. O primeiro ponto está localizado próximo a nascente, e o segundo ponto está localizado próximo a bomba de captação dessas águas. Os dois pontos distam um do outro em aproximadamente 50 metros. Esses dois se localizam aproximadamente 500 metros da área de cultivo orgânico. Essas amostragens foram realizadas em dois períodos do ano, sendo a primeira no mês de maio e a segunda amostragem no mês de setembro. Devido aos altos resultados de fósforo obtidos nas amostras de água no primeiro período de amostragem também foram retiradas amostras de solo, no segundo período de amostragem, próximo aos mesmos locais para quantificar o fósforo solúvel nas amostras de solo.

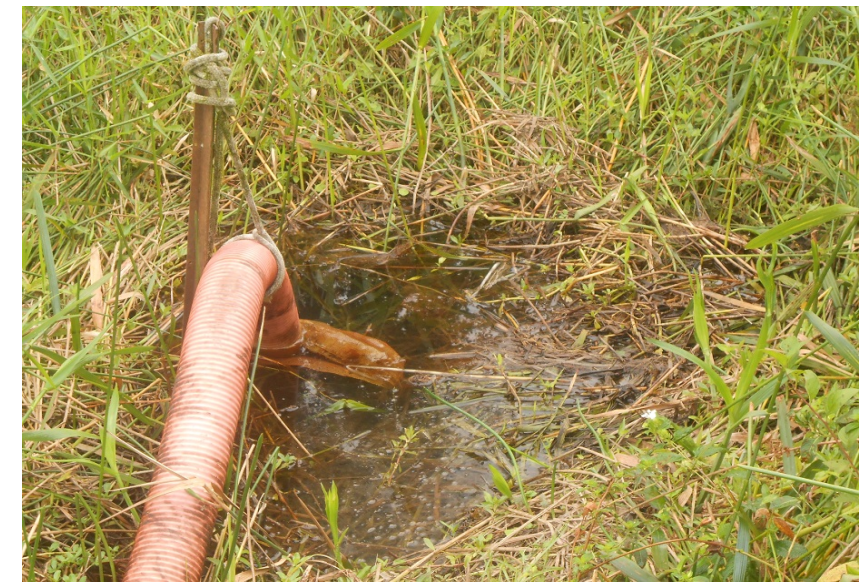

Figura 1. Bomba de captação da água utilizada para a irrigação dos produtos orgânicos.

As amostras foram transportadas para o Laboratório de Bioquímica e Microbiologia da FAFIPAR onde foram realizados ensaios físicoquímicos para quantificar alguns parâmetros (Rice et al, 2012). O elemento químico fósforo disponível foi determinado por espectrofotometria, na forma de fosfato. Após a mistura da amostra e das soluções padrões com soluções de molibdato de amônio, ácido ascórbico, ácido nítrico e glicerina ocorreu a formação da coloração azul de molibdênio (Masini, 2008). Em seguida se realizou todas as medidas dos valores de absorbância em 660nm, incluindo calibração do equipamento e também do branco. Para os ensaios com solo, este foi solubilizado em reagente água tipo IV segundo ASTM D1193 (Rice et al, 2012) com agitação mecânica e posteriormente se prosseguiu com a metodologia indicada por Masini (2008).

O nitrogênio disponível também foi determinado por espectrofotometria, sendo avaliado em três diferentes íons: amônio, nitrato e nitrito. As medidas de absorbância da primeira espécie foram determinadas em $630 \mathrm{~nm}$, após a mistura da amostra ou dos padrões com soluções de nitroprussiato de sódio, ácido fênico, hidróxido de sódio e cloro ativo com formação da coloração azul de indofenol (Standen e Taliaard, 1997; Silva et al, 2006). O nitrito foi determinado pelo método de Griess, em 540nm (Green, 1992), ou seja, adicionou-se a amostra ou os padrões alíquotas de solução de sulfanilamida e cloridrato de N-1-naftiletilenodiamina (NED) obtendo-se a coloração rósea. Posteriormente determinou-se o íon nitrato na região do infravermelho, onde foi adicionada a alíquota de 
solução de ácido clorídrico, nas amostras e nas soluções padrões. Em seguida realizou-se a medida dos valores de absorbância em 220 e $275 \mathrm{~nm}$, visto que em $275 \mathrm{~nm}$ o íon nitrato sofre interferência do carbono orgânico presente na amostra. Já em 220nm determina-se a absorbância somente de carbono orgânico.

Antes de realizar os ensaios analíticos para determinar os valores de $\mathrm{pH}$ nas amostras calibrou-se o aparelho medidor de $\mathrm{pH}$ com solução tampão pH 7,0 e com solução tampão $\mathrm{pH} 4,00$. Já para determinar o índice de turbidez da amostra o turbidimetro foi calibrado em ONTU e em 100NTU.

Todos estes ensaios analíticos foram realizados com cinco repetições, para que dessa forma os possíveis erros, que comumente ocorrem em um processo analítico, fossem minimizados. O resultado apresentado foi obtido pela média desses valores e deles foi extraído o desvio padrão.

\section{RESULTADOS E DISCUSSÕES:}

Avaliando os resultados obtidos nos
ensaios realizados para determinar a
concentração do elemento fósforo na sua forma
mais estável, ou seja, o fosfato quantificado nas
amostras, é possível afirmar que os valores
estão bastante elevados (Tabela 1) se
comparados a norma estabelecida para
ambientes lóticos pela Resolução $357 / 2005$ do
CONAMA (Brasil, 2005).

Tabela 1. Resultados obtidos do elemento fósforo na forma do ín fosfato, nos dois pontos de amostragem nos dois períodos de amostragem.

\begin{tabular}{c|c|c|c}
\hline $\begin{array}{c}\text { Ponto } \\
\text { Amostrado }\end{array}$ & $\begin{array}{c}\text { Maio } \\
\mathbf{2 0 1 3}\end{array}$ & $\begin{array}{c}\text { Setembro } \\
\mathbf{2 0 1 3}\end{array}$ & $\begin{array}{c}\text { CONAMA } \\
\text { mg L}^{-1} \mathbf{P}\end{array}$ \\
\hline A & $2,19 \pm 0,04$ & $4,28 \pm 0,02$ & 0,15 \\
\hline B & $1,23 \pm 0,04$ & $1,27 \pm 0,04$ & 0,15 \\
\hline
\end{tabular}

Também foram realizados ensaios nas amostras de solo da propriedade rural. esses resultados são apresentados na Tabela 2. Com eles se percebe que os valores observados são altos, embora o CONAMA na sua Resolução $N^{\circ}$ 420 não estipula valores de referência para esse elemento químico (Brasil, 2009).
Tabela 2. Resultados obtidos do elemento fósforo na forma do íon fosfato, nas amostras retiradas do solo.

\begin{tabular}{c|c|c}
\hline $\begin{array}{c}\text { Ponto de } \\
\text { Amostragem }\end{array}$ & $\begin{array}{c}\text { Solo } \\
\text { Fosfato }\end{array}$ & $\begin{array}{c}\text { CONAMA } \\
\text { mg Kg }^{-1} \mathbf{P}\end{array}$ \\
\hline A & $96,0 \pm 0,2$ & $\mathrm{NV}$ \\
\hline B & $79,2 \pm 0,6$ & $\mathrm{NV}$
\end{tabular}

$\mathrm{NV}=$ Não existe valor de referência para $\mathrm{P}$ no solo.

Esse fato é justificado pelos valores de fosfatos solúveis, e que estão presentes nas amostras retiradas do solo da referida propriedade. Desta forma a solubilização desse fosfato solúvel (Tremarin et al, 2008) presente no solo influenciou os resultados obtidos nas amostras retiradas dos recursos hídricos dessa propriedade rural. Outro fator que influenciou os resultados do segundo período de amostragem dessas águas foi a retirada da vegetação que havia sobre o reservatório de água utilizada para a irrigação. Desta forma não existia mais a vegetação para utilizar parte desse elemento químico para o seu desenvolvimento, e assim as concentrações de fósforo foi maior no segundo período de amostragem.

Os dados referentes ao elemento nitrogênio, na forma de nitrito, são apresentados na Tabela 3. Comparando os valores obtidos durante os ensaios analíticos com aqueles estabelecidos pela resolução 357/2005 do CONAMA, se percebe que os resultados obtidos estão muito abaixo dos valores estabelecidos, ou seja, 1000 $\mu \mathrm{g} \mathrm{L}^{-1}$, sendo que os mesmos foram quantificados, com exceção do ponto $A$ no mês de setembro, que apresentaram valores abaixo do limite de quantificação.

Tabela 3. Representação dos resultados de nitrito $\left(\mu \mathrm{g} \mathrm{L}^{-1}\right)$ que foram obtidos nos ensaios espectrofotométricos.

\begin{tabular}{c|c|c|c}
\hline $\begin{array}{c}\text { Ponto } \\
\text { Amostrado }\end{array}$ & $\begin{array}{c}\text { Maio } \\
\mathbf{2 0 1 3}\end{array}$ & $\begin{array}{c}\text { Setembro } \\
\mathbf{2 0 1 3}\end{array}$ & $\begin{array}{c}\text { CONAMA } \\
\boldsymbol{\mu g ~ L}^{-1} \mathbf{N}\end{array}$ \\
\hline A & $10,92 \pm 0,2$ & AUSENTE & 1000 \\
\hline B & $10,56 \pm 0,08$ & $10,52 \pm 0,08$ & 1000 \\
\hline
\end{tabular}

Os resultados do íon nitrato, que é a forma mais oxidada e estável do elemento nitrogênio, são apresentados na Tabela 4. Nessa tabela se 
verifica que a concentração máxima de nitrato permitida pela resolução CONAMA é $10 \mathrm{mg} \mathrm{L}^{-1}$ N. Quando são comparados os resultados obtidos se percebe que todos os valores das amostras avaliadas encontram-se abaixo dos limites máximos estabelecidos pela mesma Resolução CONAMA.

Tabela 4. Representação dos resultados de nitrato $\left(\mathrm{mg} \mathrm{L}^{-1}\right)$ que foram obtidos nos ensaios espectrofotométricos.

\begin{tabular}{c|c|c|c}
\hline $\begin{array}{c}\text { Ponto } \\
\text { Amostrado }\end{array}$ & $\begin{array}{c}\text { Maio } \\
\mathbf{2 0 1 3}\end{array}$ & $\begin{array}{c}\text { Setembro } \\
\mathbf{2 0 1 3}\end{array}$ & $\begin{array}{c}\text { CONAMA } \\
\text { mg L}^{-1} \mathbf{N}\end{array}$ \\
\hline A & $0,72 \pm 0,08$ & $1,27 \pm 0,02$ & 10 \\
\hline B & $0,40 \pm 0,04$ & $0,35 \pm 0,08$ & 10 \\
\hline
\end{tabular}

O elemento nitrogênio também foi avaliado na sua forma como íon amônio. Esse íon é obtido quando o gás amônia é solubilizado em água. O gás amônia é produzido pela decomposição de matéria orgânica em anaeróbio.

Tabela 5. Representação dos resultados de nitrogênio na forma do íon amônio ( $\mathrm{mg} \mathrm{L}^{-1}$ ) que foram obtidos nos ensaios espectrofotométricos.

\begin{tabular}{c|c|c|c}
\hline $\begin{array}{c}\text { Ponto } \\
\begin{array}{c}\text { Mmostrad } \\
\mathbf{0}\end{array}\end{array}$ & $\begin{array}{c}\text { Maio/13 } \\
\text { Nitrato }\end{array}$ & $\begin{array}{c}\text { Setembro/13 } \\
\text { Nitrato }\end{array}$ & $\begin{array}{c}\text { CONAMA } \\
\text { mg L}^{-1} \mathbf{N}\end{array}$ \\
\hline $\mathbf{A}$ & $\begin{array}{c}0,073 \pm 0,01 \\
8\end{array}$ & $0,043 \pm 0,014$ & 13,3 \\
\hline $\mathbf{B}$ & $\begin{array}{c}0,045 \pm 0,01 \\
8\end{array}$ & $0,032 \pm 0,009$ & 13,3 \\
\hline
\end{tabular}

Percebe-se pelos resultados apresentados na Tabela 5 que esse íon apresentou resultados muito abaixo dos valores preconizados pela Resolução CONAMA. Observa-se ainda que os valores do segundo período de amostragem são menores do que os do primeiro período, esse fato é explicado devido a retirada da vegetação da superfície do reservatório de irrigação.

Os últimos resultados apresentados são referentes aos ensaios de turbidez, $\mathrm{pH}$ e sólidos dissolvidos totais (Tabela 6). Os valores obtidos dos ensaios analíticos de todas as amostras apresentaram resultados dentro dos parâmetros estabelecidos pela Resolução 357/2005 do CONAMA, com exceção dos valores de pH. Esse parâmetro físico-químico apresentou valores ligeiramente inferiores aos limites mínimos estabelecidos. Esse fato é explicado pela quantidade de matéria orgânica decomposta nessas águas, provocando a diminuição dos valores de $\mathrm{pH}$ dessas águas.

Tabela 6. Resultados de turbidez, $\mathrm{pH}$ e sólidos dissolvidos totais que foram obtidos nos ensaios turbidimétricos, potenciométricos

gravimétricos.

\begin{tabular}{c|c|c|c}
\hline $\begin{array}{c}\text { Ponto de } \\
\text { Amostragem }\end{array}$ & $\begin{array}{c}\text { Turbidez } \\
\text { (NTU) }\end{array}$ & $\mathbf{p H}$ & $\begin{array}{c}\text { Sólidos } \\
\text { totais } \\
\text { (mg/L) }\end{array}$ \\
\hline $\begin{array}{c}\text { Maio/2013 } \\
\text { A }\end{array}$ & $1,20 \pm 0,48$ & $5,95 \pm 0,03$ & $0,22 \pm 0,14$ \\
\hline $\begin{array}{c}\text { Maio/2013 } \\
\text { B }\end{array}$ & $1,51 \pm 0,60$ & $5,97 \pm 0,02$ & $0,21 \pm 0,11$ \\
\hline $\begin{array}{c}\text { Setembro/2013 } \\
\text { A }\end{array}$ & $1,80 \pm 0,03$ & $5,90 \pm 0,10$ & $0,15 \pm 0,05$ \\
\hline $\begin{array}{c}\text { Setembro/2013 } \\
\text { B }\end{array}$ & $0,85 \pm 0,08$ & $5,54 \pm 0,13$ & $0,16 \pm 0,07$ \\
\hline CONAMA & 40 & 6,0 a 9,0 & 0,5 \\
\hline \multicolumn{2}{c}{}
\end{tabular}

\section{CONCLUSÕES:}

A partir dos resultados obtidos nesse procedimento experimental se percebe que a propriedade rural estudada não utiliza fertilizantes industriais no cultivo de suas culturas, desta forma se tem indícios que a mesma efetua a Agricultura Orgânica. Esse parecer se baseia no fato de que os possíveis íons inorgânicos nitrogenados, que poderiam ser adicionados intencionalmente para auxiliar no crescimento de plantas, aparecem em níveis muito abaixo daqueles preconizados pelas Resoluções 357/2005 e 420/2009 CONAMA que norteiam o setor. Já o íon inorgânico fosfatado que é preponderante utilizado como um macronutriente apresenta-se em níveis elevados, mas se percebe que os mesmos estão presentes de forma natural na propriedade, e não adicionado de forma antrópica.

Com estes resultados pode-se afirmar que, mesmo os valores de fósforo presentes nas águas de irrigação da propriedade orgânica estudada estar acima dos valores estabelecidos pela Resolução № 357/2005 do CONAMA, os mesmos não ocorreram devido à contaminação antrópica. 


\section{AGRADECIMENTOS:}

Os autores agradecem a FAFIPAR pelo apoio constante nos trabalhos realizados por esse grupo de pesquisa, ao Fundo Paraná pelo apoio financeiro ao Projeto Paranaense de Certificação de Produtos Orgânicos - Fase II, bem como pela bolsa de iniciação científica e ao proprietário do "Xítio do Xaxo" Sr. Constâncio.

\section{REFERÊNCIAS:}

1. Brasil, Lei № 10831 de 23 de dezembro de 2003, dispõe sobre a agricultura orgânica e dá outras providências. Diário Oficial da União de 24/12/2003, Executivo.

2. Brasil, Resolução CONAMA n ${ }^{\circ} 357$, de 17 de março de 2005 - Dispõe sobre a classificação dos corpos de água e diretrizes ambientais para o seu enquadramento, bem como estabelece as condições e padrões de lançamento de efluentes, e dá outras providências. Diário Oficial da União de 18/03/2005, Executivo.

3. Brasil, Ministério da Saúde. Secretaria de Vigilância em Saúde.Vigilância e controle da qualidade da água para consumo humano. Ministério da Saúde, Secretaria de Vigilância em Saúde. - Brasília : Ministério da Saúde, 2006.

4. Brasil, Resolução CONAMA $n^{\circ} 420$, de 28 de dezembro de 2009 - Dispõe sobre critérios e valores orientadores de qualidade do solo quanto à presença de substâncias químicas $\mathrm{e}$ estabelece diretrizes para o gerenciamento ambiental de áreas contaminadas por essas substâncias em decorrência de atividades antrópicas. Diário Oficial da União de 29/12/2009, Executivo.

5. Carvalho, M. C., Agujaro, L. F., Pires, D. A., Picoli, C.,. Manual de cianobactérias planctônicas: legislação, orientações para o monitoramento e aspectos ambientais. São Paulo: CETESB, 2013.

6. Field, C. B.; Behrenfeld, M. J.; Randerson, J. T.; Falkowski, P. Primary Production of the
Biosphere: Integrating Terrestrial and Oceanic Components. Science. Vol. 281, p. 237-240, 1998.

7. Green, L. C.; Wagner, D. A.; Glogowski, J.; Skipper, P. L.; Wishnok, J. S.; Tannenbanm, $\mathrm{S}$. R. Analysis of nitrate, nitrite, and $\left[{ }^{15} \mathrm{~N}\right]$ nitrate in biological fluids. Analytical Biochemistry, Vol. 126, n. 1, p. 131-138, 1982.

8. Masini, J. C. Demonstrando os Fundamentos, Potencialidades e Limitações da Análise por Injeção Seqüencial. Química Nova, Vol. 31, n. 3, p. 704-708, 2008.

9. Nascimento, T. S.; Pereira, R. O. L.; Mello, H. L. D.; Costa, J. Metemoglobinemia: do Diagnóstico ao Tratamento. Revista Brasileira de Anestesiologia, Vol. 58, n. 6, p. 651-664, 2008.

10. Rice, E. W.; Baird, R. B.; Eaton, A. D.; Clesceri, L. S. (ed.) Standard Methods for the Examination of Water and Wastewater. 22nd Edition. Washington: American Public Health Association, 2012.

11. Schindler, D. W.; Hecky, R. E.; Findlay, D. L.; Stainton, M. P.; Parker, B. R.; Paterson, M. J.; Beaty, K. G.; Lyng, M.; Kasian, S. E. M. Eutrophication of lakes cannot be controlled by reducing nitrogen input: Results of a 37year whole-ecosystem experiment. Proceedings of the National Academy of Sciences of the United States of America. Vol. 105, n. 32, p. 11254-11258, 2008.

12. Silva, L. I. D. da; Carneiro, M. C.; Emídio, V. dos S.; Junior, S. de S. H.; Monteiro, M. I. C. Determinação das Formas do Nitrogênio e Nitrogênio Total em Rochas-Reservatório de Petróleo com Destilação por Arraste de Vapor e Método do Indofenol. Química Nova, Vol. 29, n. 1, p. 46-51, 2006.

13. Standen, J. F. van; Taliaard, R. E.; Determination of ammonia in water and industrial effluent streams with the indophenol blue method using sequential injection analysis. Analytica Chimica Acta, Vol. 344, n. 3, p. 281-289, 1997. 
14. Tremarin, P. I.; Ludwing, T. A. V.; Filho, H. M. Eunotia Ehrenberg (Bacillariophyceae) do Rio Guaraguaçu, Litoral do Paraná, Brasil. Acta Botanica Brasilica, Vol. 22, n. 3, p. 845862, 2008.

15. Von Sperling, M. Introdução à qualidade das águas e ao tratamento de esgotos. DESA - Departamento de Engenharia Sanitária e Ambiental, Universidade Federal de Minas Gerais, 1996.

16. http://www.inea.rj.gov.br/fma/qualidadeagua.asp acesso em $10 \mathrm{~h} 30$ de 02/07/13 